\title{
Morphological and Molecular Characterization of Explanatum Explanatum from Cattle and Buffaloes in Myanmar
}

\author{
Madoka ICHIKAWA ${ }^{1,2,3)^{*}}$, Daisuke KONDOH ${ }^{4)}$, Saw BAWN ${ }^{5)}$, Ni Ni MAW6), Lat Lat HTUN ${ }^{5)}$, Myint THEIN ${ }^{6}$, \\ Aung GYI $^{6}$, Kyaw SUNN ${ }^{6}$, , Ken KATAKURA ${ }^{7)}$ and Tadashi ITAGAKI ${ }^{2}$ \\ ${ }^{1)}$ National Research Center for Protozoan Diseases, Obihiro University of Agriculture and Veterinary Medicine, Nishi-2-13 Inada-cho, \\ Obihiro, Hokkaido 080-8555, Japan \\ ${ }^{2)}$ Laboratory of Veterinary Parasitology, Faculty of Agriculture, Iwate University, 3-18-8 Ueda, Morioka 020-8550, Japan \\ ${ }^{3)}$ Research Fellow of the Japan Society for the Promotion of Science, \\ 4) Department of Basic Veterinary Science, United Graduate School of Veterinary Science, Gifu University, 1-1 Yanagido, Gifu 501-1193, \\ Japan \\ ${ }^{5)}$ Department of Pharmacology and Parasitology, University of Veterinary Science, Yezin, Naypyidaw 05282, Myanmar \\ ${ }^{6}$ Livestock Breeding and Veterinary Department, Insein, Yangon 11011, Myanmar \\ ${ }^{7)}$ Laboratory of Parasitology, Department of Disease Control, Graduate School of Veterinary Medicine, Hokkaido University, Kita 18 , \\ Nishi 8, Sapporo, Hokkaido 060-0818, Japan
}

(Received 4 September 2012/Accepted 16 October 2012/Published online in J-STAGE 30 October 2012)

ABSTRACT. A robust molecular marker is needed for discrimination of amphistome species, because identification based on morphology alone requires specialized knowledge and techniques. In this study, we performed morphological and molecular characterization of Explanatum explanatum, a species that causes severe liver damage in definitive host species. Fifty-five adult amphistomes were collected from cattle and water buffaloes in Myanmar. Eighteen of the amphistomes, arbitrarily chosen, were morphologically identified as E. explanatum using sagittal sections. All of the 55 amphistome isolates had identical second internal transcribed spacer (ITS2) of ribosomal DNA sequences; these sequences differed at 7 nucleotide sites from those of the closest species, Paramphistomum leydeni. Our data indicate that the ITS2 sequence could be a useful molecular marker for epidemiological studies on E. explanatum.

KEY WORDS: amphistome, Explanatum, ITS2, molecular marker, morphological characterization.

doi: 10.1292/jvms.12-0389; J. Vet. Med. Sci. 75(3): 309-314, 2013

Amphistomes that have been detected in ruminants in the world comprise more than 70 species. Most of these species are pathogens that cause intestinal paramphistomiasis, in which the immature amphistomes cause the most serious morbidity in ruminants. Adult amphistomes of the genus Explanatum have been detected in the bile ducts of domestic ruminants where they inflict severe damage to the epithelium of the bile duct $[2,7,10]$. Explanatum amphistomes attach to the epithelium using the acetabulum (ventral sucker) and produce "granulomatous nodules" that are infiltrated by numerous inflammatory cells [3]. The infection causes substantial economic losses via increased mortality in affected domestic ruminants, reduction in growth rates and decreased production of dairy products. It is, therefore, very important to make an accurate diagnosis of infection with Explanatum amphistomes, as well as conducting epidemiological surveys to obtain a better picture of the infection dynamics of this species. Although diagnosis of amphistome infection relies on detection of parasite eggs during fecal examina-

\footnotetext{
*Correspondence to: IchiKawa, M., National Research Center for Protozoan Diseases, Obihiro University of Agriculture and Veterinary Medicine, Nishi-2-13, Inada-cho, Obihiro, 080-8555, Japan.

e-mail: michikawa@obihiro.ac.jp

(C)2013 The Japanese Society of Veterinary Science
}

tion, it is impossible to identify which species is present from morphological analysis of the eggs alone. Even when adult amphistomes are identified in infected hosts, morphological identification of the adults still requires specialized knowledge and techniques [9]. Therefore, identification of a reliable molecular marker for species identification is urgently required. Current molecular characterization methods facilitate accurate identification of parasitic helminths [1]. The second internal transcribed spacer (ITS2) of ribosomal DNA has been shown to be a useful genetic marker for species identification of amphistomes $[4,6,8]$. In addition, PCR amplification of DNA from individual eggs obtained from three amphistome species successfully generated ITS2 nucleotide sequences [4]. In this study, we performed a careful morphological characterization of Explanatum amphistomes collected from domestic ruminants in Myanmar, followed by molecular characterization of their ITS2 nucleotide sequences.

\section{MATERIALS AND METHODS}

Fifty-five adult amphistomes were collected from the bile ducts of 20 infected hosts (cattle and buffaloes) at slaughterhouses in Yangon and Myitkyina, Myanmar, in 2009 and 2010. The isolates were preserved in $70 \%$ ethanol until use (Table 1). We prepared sagittal sections (Laurer's canal, excretory pore and terminal genitalium) of $5 \mu \mathrm{m}$ thickness 
for 18 amphistomes from 6 of the hosts. The samples were embedded in paraffin and stained with hematoxylin and eosin. Morphological identification was performed according to the existing keys described by Jones [5] at the genus level, and by Sey [9] at the species level. We measured body length and width together with the size of the internal organs using an optical microscope, and compared our observations to those of Sey [9].

We performed a molecular analysis on the 55 amphistomes. Total DNA was extracted from individual amphistomes using a High Pure PCR Template Preparation Kit (Roche, Mannheim, Germany), according to the manufacturer's instructions. DNA was stored at $-20^{\circ} \mathrm{C}$ until use. We used the acetabulum (ventral sucker) of the amphistomes without the uteri and ootypes to exclude sperm from other amphistomes. Deparaffinized acetabulum was used for the 18 amphistomes which were prepared for sagittal sections. DNA fragments of the nuclear ITS2 region, including partial $5.8 \mathrm{~S}$ and $28 \mathrm{~S}$ ribosomal RNA genes (442 bp), were amplified by the polymerase chain reaction (PCR) using ITS2-F (5'-TGTGTCGATGAAGAGCGCAG-3') and ITS2-R (5'-TGGTTAGTTTCTTTTCCTCCGC-3') primers. PCR was performed in a $25 \mu \mathrm{l}$ reaction volume containing $2 \mu \mathrm{l}$ of DNA template, $0.2 \mathrm{mM}$ of each dNTP, $0.1 \mu \mathrm{M}$ of each primer, 1.25 U of GoTaq DNA polymerase (Promega, Madison, WI, U.S.A.) and the manufacturer-supplied reaction buffer. The thermal program was $94^{\circ} \mathrm{C}$ for $90 \mathrm{sec}, 30$ cycles of $94^{\circ} \mathrm{C}$ for $30 \mathrm{sec}, 63^{\circ} \mathrm{C}$ for $30 \mathrm{sec}$ and $72^{\circ} \mathrm{C}$ for $1 \mathrm{~min}$, and $72^{\circ} \mathrm{C}$ for $10 \mathrm{~min}$. After purification using a High Pure

Table 1. Explanatum samples used in this study

\begin{tabular}{|c|c|c|c|}
\hline Location & Host codes & $\begin{array}{c}\text { Number of } \\
\text { amphistomes }\end{array}$ & $\begin{array}{l}\text { Number of the } \\
\text { amphistomes } \\
\text { prepared for } \\
\text { sagittal sections }\end{array}$ \\
\hline \multirow{10}{*}{ Yangon } & A & 2 & 0 \\
\hline & B & 4 & 3 \\
\hline & $\mathrm{C}$ & 5 & 3 \\
\hline & $\mathrm{D}$ & 2 & 0 \\
\hline & $\mathrm{E}$ & 1 & 0 \\
\hline & $\mathrm{F}$ & 2 & 0 \\
\hline & $\mathrm{G}$ & 5 & 3 \\
\hline & $\mathrm{H}$ & 1 & 0 \\
\hline & I & 2 & 0 \\
\hline & $\mathrm{J}$ & 2 & 0 \\
\hline \multirow{10}{*}{ Myityina } & $\mathrm{K}$ & 5 & 3 \\
\hline & $\mathrm{L}$ & 2 & 0 \\
\hline & M & 2 & 0 \\
\hline & $\mathrm{N}$ & 5 & 3 \\
\hline & $\mathrm{O}$ & 2 & 0 \\
\hline & $\mathrm{P}$ & 2 & 0 \\
\hline & $\mathrm{Q}$ & 2 & 0 \\
\hline & $\mathrm{R}$ & 5 & 3 \\
\hline & $\mathrm{S}$ & 2 & 0 \\
\hline & $\mathrm{T}$ & 2 & 0 \\
\hline Total & & 55 & 18 \\
\hline
\end{tabular}

PCR Cleanup Micro Kit (Roche, Mannheim, Germany), the nucleotide sequences of the ITS2 region (442 bp) were directly sequenced in both directions with a BigDye Terminator v3.1 Cycle Sequencing Kit (Applied Biosystems, Foster City, CA, U.S.A.). The sequencing reactions were run on a 3500 Genetic Analyzer (Applied Biosystems). A neighborjoining (NJ) phylogram was constructed by PAUP 4.0b10 [11]. The sequences of amphistomes deposited in GenBank were used as references. The ITS2 sequences were aligned using GENETYX ver. 10. 0. 2 (Genetyx, Tokyo, Japan). We deleted partial sequences of the ITS2 region from the NJ tree to include the shortest reference sequences (359 bp). Bootstrap analyses were conducted using 1,000 replicates.

\section{RESULTS}

We observed severe damage to the bile ducts of the infected hosts as previously reported [3, 7]; this included clearly visible "granulomatous nodules" on the thickened epithelia where the amphistomes had attached by means of their acetabulums (Fig. 1). In the sagittal sections, we observed that the Laurer's canal opened posteriorly to the excretory pore (Fig. 2), thus the amphistomes were identified as belonging to the Paramphistominae subfamily. We observed that the acetabulum was enormous (Fig. 3A), and the pars musculosa weakly developed (Fig. 3B); thus, the amphistomes were identified as belonging to the genus Explanatum. Further
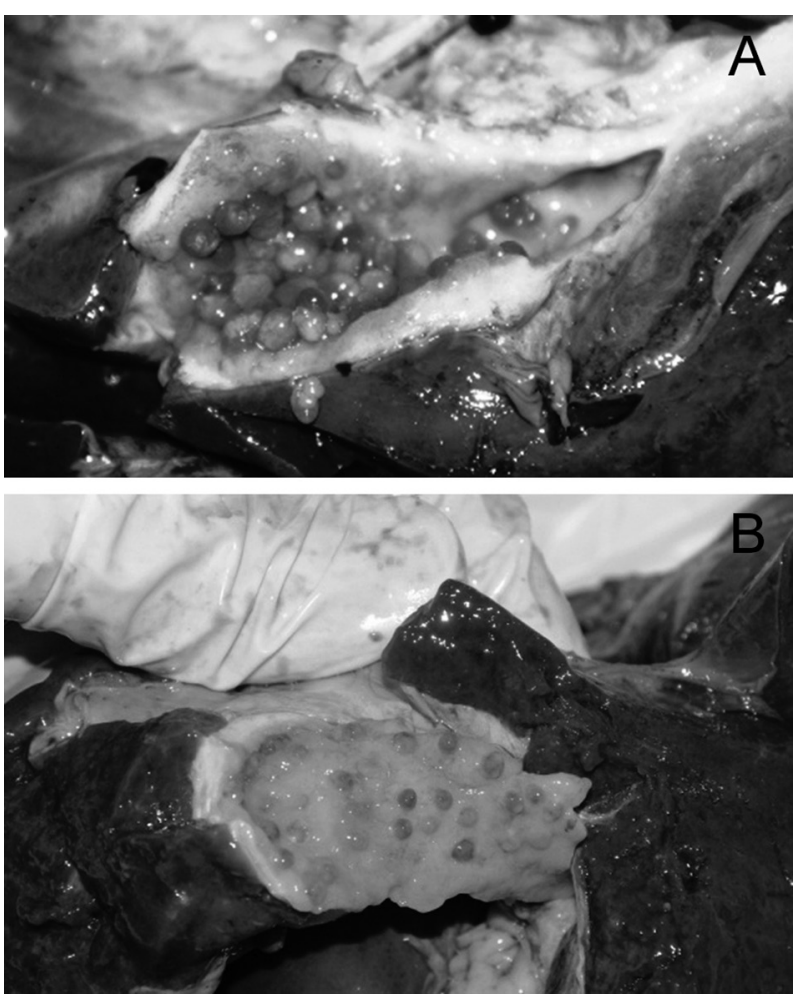

Fig. 1. A bile duct containing numerous amphistomes (A) and "dome-like protuberances" after removal of the amphistomes (B). 

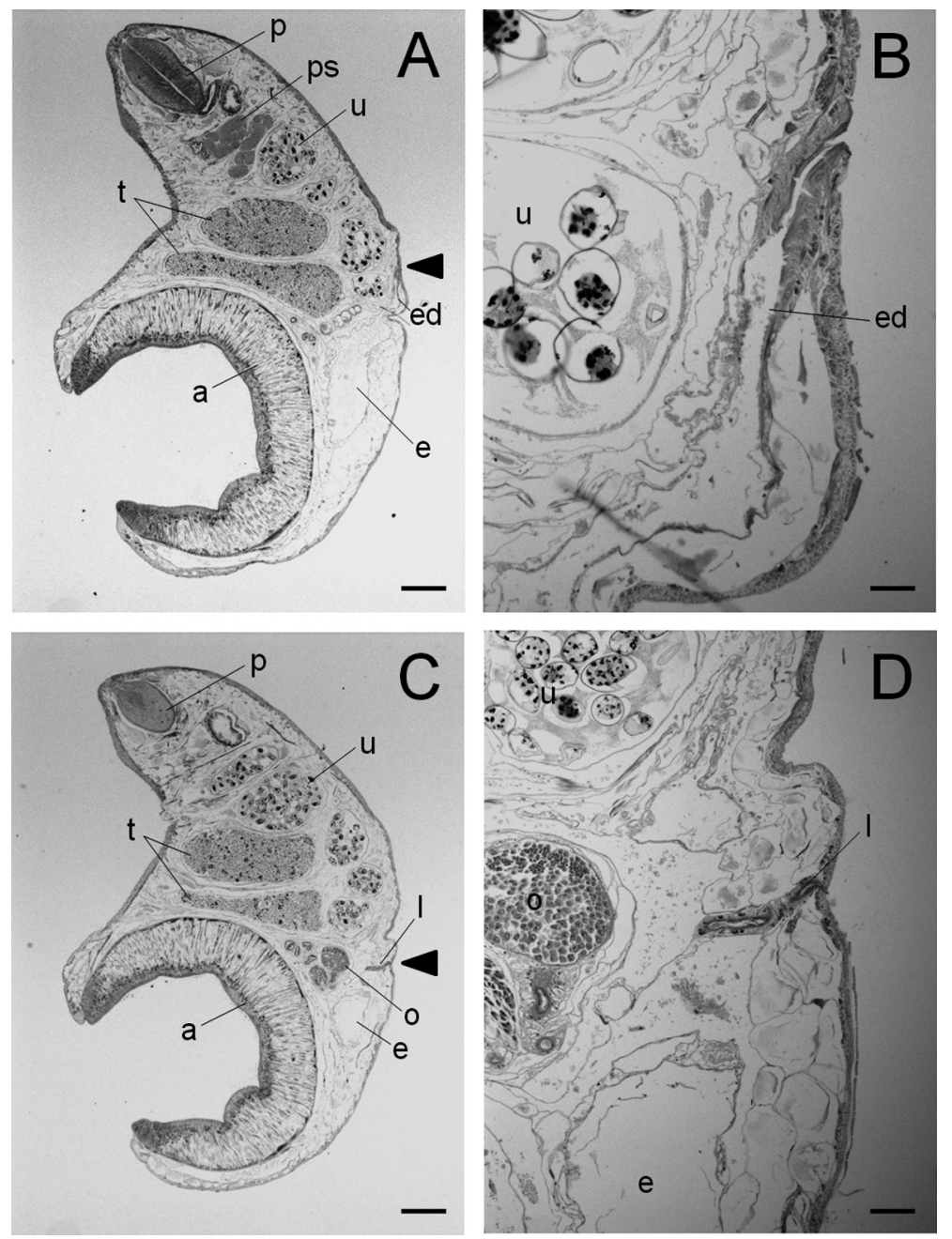

Fig. 2. Representative sagittal sections at the level of the excretory pore (A and B) and Laurer's canal (C and D). Arrowheads indicate the excretory pore (A) and the orifice of the Laurer's canal (C), respectively. p: pharynx, ps: pars seminalis, u: uterus, t: testis, ed: excretory duct, e: excretory bladder, a: acetabulum, o: ovary, 1: Laurer's canal, bars: $5 \mathrm{~mm}$ (A and C) and $1 \mathrm{~mm}$ (B and D).

confirmation was provided by the terminal genitalium, which was the Explanatum type (Fig. 3C); thus, the amphistomes were identified as E. explanatum. The morphometric values for the 6 amphistomes (which were prepared well for measurement), are summarized in Table 2. The remaining 12 amphistomes could not be measured, because some organs were missing from the sections. Although the morphological characteristics described above were completely identical to the existing keys [5,9], the morphometrical values of the amphistomes slightly varied from the morphological descriptions of Sey [9].

The nucleotide sequences of the ITS2 region (442 bp) had no variation within the 55 amphistomes isolated; thus, a representative sequence was deposited in GenBank (AB743577). The nucleotide sequences of the amphistomes in the NJ tree scarcely fell into a genus specific clade, mak- ing phylogenetic relationships among them impossible to infer from their ITS2 sequences alone. Nonetheless, the nucleotide sequence of E. explanatum was closest to that of the Paramphistomum leydeni sequence (HM209067) (Fig. 4); the sequences differed between these species at 7 nucleotide sites.

\section{DISCUSSION}

In this study, we performed a careful morphological characterization of amphistomes collected from cattle and buffaloes from Myanmar. This analysis showed they were all $E$. explanatum. However, the morphometric values we obtained were slightly different from Sey [9]. Values obtained from morphological measurements may vary as there are many factors that can affect such measurements, including amphis- 

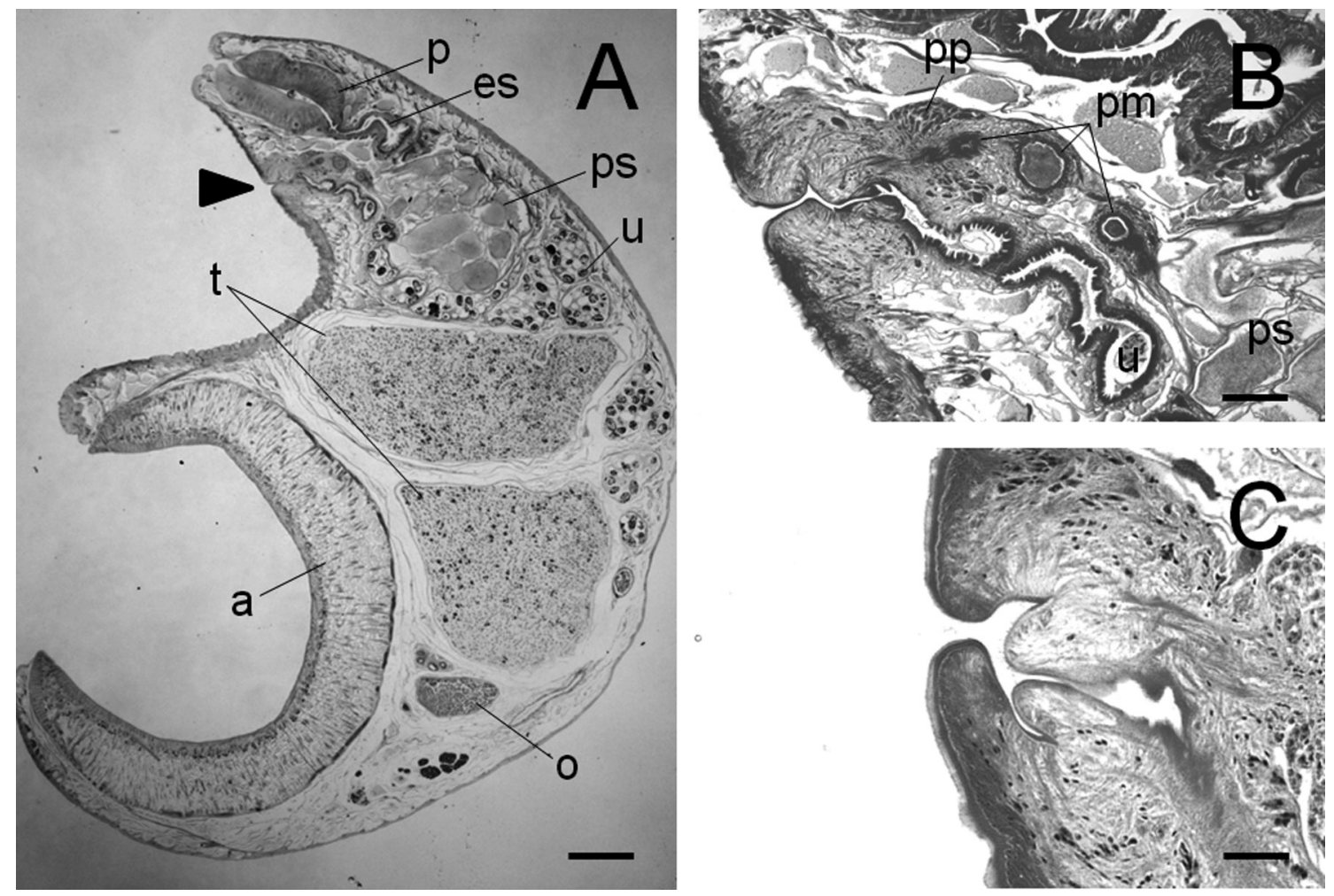

Fig. 3. (A) Representative sagittal sections at the level of the terminal genitalium. Arrowhead indicates the genital pore. (B) An enlarged image around the terminal genitalium. (C) A terminal genitalium of the typical Explanatum type. p: pharynx, es: esophagus, ps: pars seminalis, u; uterus, t: testis, a: acetabulum, o: ovary, pm: pars musculosa, pp: pars prostatica. bars: $5 \mathrm{~mm}$ (A), $1.3 \mathrm{~mm}(\mathrm{~B}), 0.6 \mathrm{~mm}(\mathrm{C})$.

Table 2. Morphometric values of the 6 amphistomes measured in this study

\begin{tabular}{lcc}
\hline & Samples $(\mathrm{n}=6)$ & Explanatum explanatum $^{*}$ \\
\hline Body length & $5.30-7.39 \mathrm{~mm}$ & $6.90-13.6 \mathrm{~mm}$ \\
Body width dorsal direction & $3.38-4.56 \mathrm{~mm}$ & $3.20-6.30 \mathrm{~mm}$ \\
Acetabulum & $3.01-4.02 \mathrm{~mm}$ & $3.26-4.63 \mathrm{~mm}$ \\
Pharynx & $0.79-1.11 \mathrm{~mm}$ & $0.68-0.92 \mathrm{~mm}$ \\
Esophagus & $0.59-0.76 \mathrm{~mm}$ & $0.76-0.98 \mathrm{~mm}$ \\
Anterior testis & & \\
$\quad$ long & $0.61-1.29 \mathrm{~mm}$ & $1.02-1.63 \mathrm{~mm}$ \\
$\quad$ dorsal direction & $1.49-2.46 \mathrm{~mm}$ & $1.26-2.73 \mathrm{~mm}$ \\
Posterior testis & & \\
$\quad$ long & $0.48-1.36 \mathrm{~mm}$ & $1.22-1.76 \mathrm{~mm}$ \\
$\quad$ dorsal direction & $0.69-2.47 \mathrm{~mm}$ & $1.98-2.74 \mathrm{~mm}$ \\
Ovary & & \\
$\quad$ long & $0.29-0.66 \mathrm{~mm}$ & $0.35-0.63 \mathrm{~mm}$ \\
$\quad$ dorsal direction & $0.17-0.63 \mathrm{~mm}$ & $0.42-0.54 \mathrm{~mm}$ \\
Eggs (n=18**) & & \\
$\quad$ length & $0.103-0.138 \mathrm{~mm}$ & $0.117-0.131 \mathrm{~mm}$ \\
$\quad$ width & $0.054-0.070 \mathrm{~mm}$ & $0.072-0.081 \mathrm{~mm}$ \\
\hline
\end{tabular}

* Sey [9].

** Three eggs were measured per sample.

tome age, fixation status (relaxed or contracted), and slight angle changes during preparation of the sagittal sections. It has been suggested, therefore, that species identification should not be based on measurement values alone. According to Sey [9], the genus Explanatum includes 2 additional species, E. bathycotyle and E. anisocotyle, which coexist 


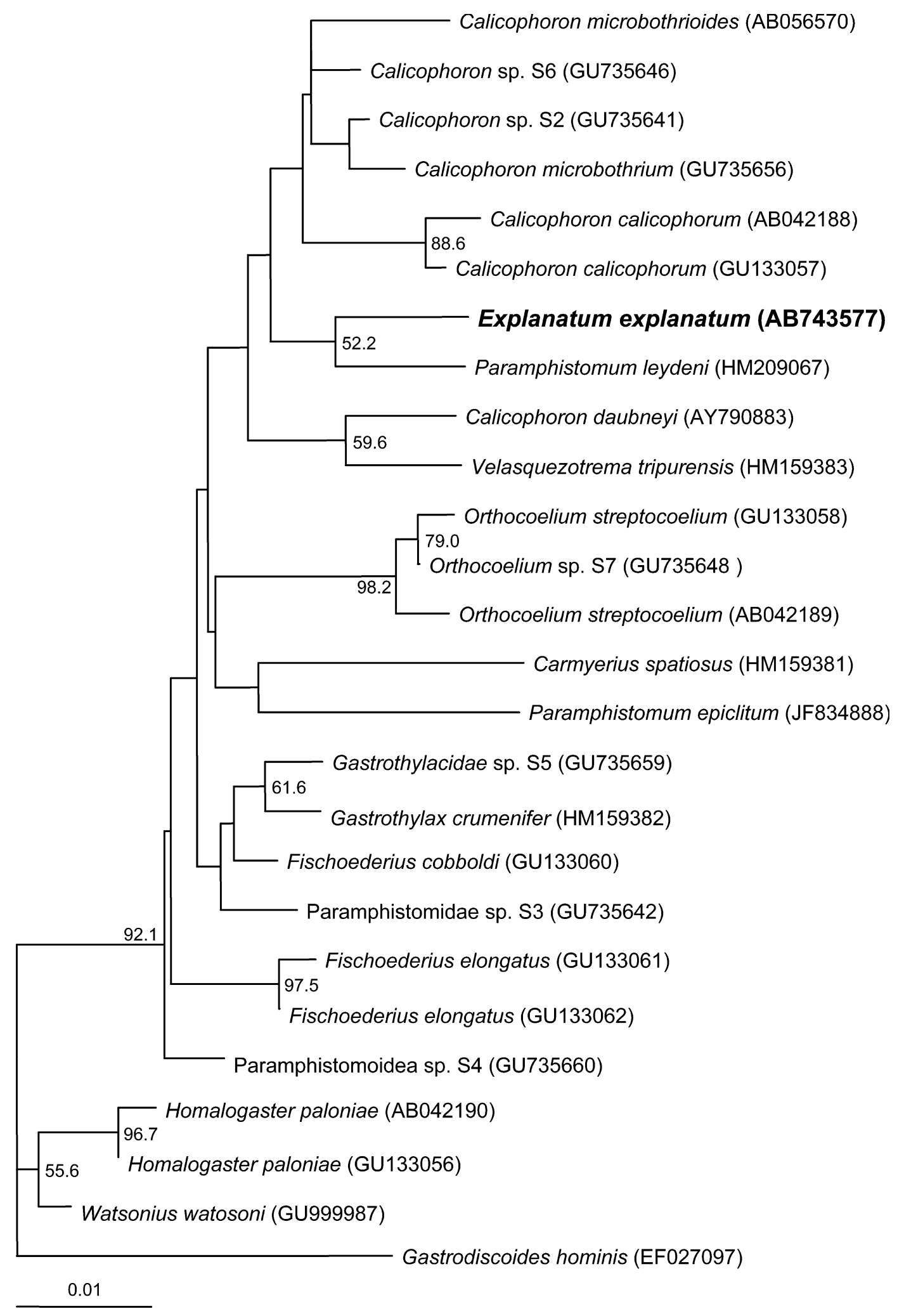

Fig. 4. A neighbor-joining phylogram based on nucleotide sequences of the second internal transcribed spacer of ribosomal DNA (ITS2). Bootstrap values higher than 50\% are shown on the tree nodes. The sequence of Explanatum explanatum is represented by bold gothic font. 
with E. explanatum in Asian countries. The author describes that terminal genitalium is the Gracile type in E. bathycotyle, and that pharynx and acetabulum are very close together in E. anisocotyle. In this study, no amphistomes displayed any morphological characteristics of these 2 species. However, we doubt that it would be useful to include these points of differentiation for the 2 species, because these points might be affected by the factors described above (i.e., amphistome age, fixation status (relaxed or contracted), and slight angle changes during preparation of the sagittal sections). A further study of Explanatum amphistomes with different geographical origins would make a solution on our question.

In this study, 55 amphistomes isolates displayed no variation in the ITS2 region (442 bp), and differed at 7 nucleotide sites from the closest species. Thus, the ITS2 region could be useful as a species identification marker for E. explanatum. It has been reported that the ITS2 region can be amplified from individual amphistome eggs [4]. Hence, the nucleotide sequence data obtained in this study have strong potential to play an important role in epidemiological studies on $E$. explanatum.

ACKNOWLEDGMENTS. We are grateful to Dr. Khin Aung and the staff of Livestock Breeding and Veterinary Department in Myitkyina for their invaluable help collecting the amphistomes. This study was supported in part by the Japan Society for the Promotion of Science for a Japanese Junior Scientist and by a Grant-in-Aid for Scientific Researchers (B) (nos. 22405037 and 23405044).

\section{REFERENCES}

1. Blair, D., Xu, Z. B. and Agatsuma, T. 1999. Paragonimiasis and the genus Paragonimus. Adv. Parasitol. 42: 113-222. [Medline]
[CrossRef]

2. Fukui, T. 1929. Studies on Japanese amphistomatous parasites, with revision of the group. Jpn. J. Zool. 2: 219-351.

3. Haque, M., Mohan, C. and Ahmad, I. 2011. Natural trematode infection in liver of water buffalo (Bubalus bubalis): histopathological investigation. J. Parasit. Dis. 35: 50-53. [Medline] [CrossRef]

4. Itagaki, T., Tsumagari, N., Tsutsumi, K. and Chinone, S. 2003. Discrimination of three amphistome species by PCR-RFLP based on rDNA ITS2 markers. J. Vet. Med. Sci. 65: 931-933. [Medline] [CrossRef]

5. Jones, A. 2005. Superfamily Paramphistomoidea Fischoeder, 1901. pp. 221-356. In: Keys to the Trematoda vol. 2, 1st ed. (Jones, A., Bray, R. D. and Gibson, D. I. eds.), CABI Publishing, Massachusetts.

6. Lotfy, W. M., Brant, S. V., Ashmawy, K. I., Devkota, R., Mkoji, G. M. and Loker, E. S. 2010. A molecular approach for identification of paramphistomes from Africa and Asia. Vet. Parasitol. 174: 234-240. [Medline] [CrossRef]

7. Mazahery, Y., Razmyar, J. and Hoghooghi-Rad, N. 1994. Explanatum explanatum (Creplin, 1847) Fukui, 1929, in buffaloes in the Ahwaz area, southeast Iran. Vet. Parasitol. 55: 149-153. [Medline] [CrossRef]

8. Rinaldi, L., Perugini, A. G., Capuano, F., Fenizia, D., Musella, V., Veneziano, V. and Cringoli, G. 2005. Characterization of the second internal transcribed spacer of ribosomal DNA of Calicophoron daubneyi from various hosts and locations in southern Italy. Vet. Parasitol. 131: 247-253. [Medline] [CrossRef]

9. Sey, O. 1991. CRC Handbook of the Zoology of Amphistomes, 1 st ed., CRC Press, Florida.

10. Singh, K. S. 1958. A redescription and life-history of Gigantocotyle explanatum (Creplin, 1847) Nasmark, 1937 (Trematoda; Paramphistomidae) from India. J. Parasitol. 44: 210-224. [Medline] [CrossRef]

11. Swofford, D. L. 2001. PAUP*. Phylogenetic Analysis using Parasimony and Other Methods Ver. 4.0 Beta. Sunderland, Massachussetts: Sinauer Associates. 